\title{
An Alternative Strategy for Sustaining Innovations of Incumbent Firms
}

\author{
Murat Kayak \\ University of Naples Federico II, Italy \\ murat.kayak@unina.it
}

\begin{abstract}
Innovation is a prominent phenomenon that enables a firm to gain a competitive advantage against its rivals. However, this does not mean that being innovative allows a firm to perform better. Although innovation has been investigated in the literature, the types of innovations still remain esoteric. As discussed in the literature, there are different kinds of innovations. Different kinds of innovation require different kinds of business models and may have varying impacts on consumer product decisions. First, this study seeks to highlight the distinction between sustaining and disruptive innovations. Second, this study offers a conceptual framework for the antecedents of sustaining innovations. Theoretical and practical implications are discussed in the light of observations.
\end{abstract}

Keywords: The structure of innovation kinds, incumbent firm performance.

\section{INTRODUCTION}

Innovation is a prominent phenomenon that enables a firm to gain a competitive advantage against its rivals (Bartel \& Garud, 2009). However, this does not mean that being innovative allows a firm to perform better. (Kim et al., 2015). Although innovation has been investigated in the literature, the types of innovations still not understood well (Kunz et al., 2011). As discussed, there are different types of innovations (e.g., Garcia \& Calantone, 2012; Danneels, 2004; Schmidt \& Druehl, 2008; Tellis, 2006; Yu \& Hang, 2010). Different kinds of innovation require different kinds of a business model (Markides, 2006) and may have varying impacts on consumer product choices (Reinhardt \& Gurtner, 2015). As noted by Danneels (2004), it is essential for academics to draw a very thorough definition and classification of technological innovation types.

The past research concluded that perceived innovation is an important variable for the product decisions of consumers (e.g., Kim et al., 2015; Kunz et al., 2011). However, as noted, innovation can be of different types, and academics sometimes fail to focus on such differences as argued by Garcia and Calantone (2002). As they assert, "Academics generally believe that they have begun to understand the process of developing innovations and it doesn't matter what they call them; new innovations smell just as sweet by any other name." (p. 110). For example, Reinhardt \& Gurtner (2015) investigated differences and similarities between early adopters of disruptive innovations and early adopters of sustaining innovations. They found that early adopters of disruptive innovations are more knowledgeable of the product domain. In contrast, consumers who purchase sustaining innovations relatively early are more involved in the product domain. Their study suggests that managers must address early adopters differently and differentiate their product development and marketing strategy in accordance with the type of innovation. What is really a disruptive innovation? Christensen et al. (2015, p. 4) argued that "There's another troubling concern: In our experience, too many people who speak of "disruption" have not read a serious book or article on the subject." According to Christensen et al. (2015), "The first minicomputers were disruptive not merely because they were low-end upstarts when they appeared on the scene, nor 
because they were later heralded as superior to mainframes in many markets; they were disruptive by virtue of the path they followed from the fringe to the mainstream" (p. 6).

There is a misconception about sustaining and disruptive innovations in the literature (Christensen et al., 2015). Innovations can be such as sustaining innovation, disruptive innovation, continuous innovation, breakthrough innovation or radical innovation. In fact, disruptive innovations are being introduced by Christensen (1997) as he showed how new technologies cause great firms to fail. Taking the example of launching a new product to deepen understanding, when a firm launches a new product to a specific market for sustaining innovation, it first encroaches the high end of the existing market and then diffuses downwards as it converses with disruptive technologies (Schimdt \& Druehl, 2008, p. 348). Prange and Schlegelmilch (2018) asserted that almost no business can survive without innovation. They claimed that when it comes to creating innovative strategies, managers are often left alone to decide which kinds of innovation to implement as they refer to this scenario as an innovation dilemma. They introduced a cube solution for firm managers. Accordingly, I concentrate in this paper on the notable distinction between sustaining innovations and disruptive innovations. Whereas there are no doubts that disruptive innovation increases firm performance over time, a sustaining innovation role is more questionable. With an inductive approach, first, this study seeks to highlight the distinction between sustaining and disruptive innovations. Second, this study introduces a conceptual framework for the antecedents of sustaining innovations. Theoretical and practical implications are discussed in the light of observations.

\section{THEORETICAL BACKGROUND}

\section{Definition of the terms}

Firms need to rely on a new market instead of the existing market to run away from the competition as argued by Kim and Mauborgne (2005). They concluded that firms should develop a new market space instead of continuing to innovate in the same market. Similarly, Moon (2010) asserted that a firm should attempt to discover a way to deliver a product that is meaningfully different instead of adopting the same possibilities of its rivals. To prepare an uncontested market space, an in-depth understanding of kinds of innovation is crucial (Kim \& Mauborgne, 2005). This research focuses on the notable distinction between sustaining and disruptive innovations, so the terms will be defined in the next paragraph.

Sustaining innovations are usually defined as "... innovations that make a product or service perform better in ways that customers in the mainstream market already value" (Christensen \& Overdorf, 2000, p. 72). Disruptive innovations are usually defined as "... innovations that prepare an entirely new market through the introduction of a new kind of product or service, one that's actually worse initially, as judged by the performance metrics that mainstream customers value" (Christensen \& Overdorf, 2000, p. 72).

Christensen (1997) argues that continuously increasing the performance of an existing product for existing customers' results leading firms to fail. According to him, leading firms have excellent-management as they are able to improve the existing products continuously, however, this is the greatest error that the incumbents' firms doing because this results in them to fail. He highlights four main major issues with respect to the management of leading firms. The first, leading firms are to keep listening to their customers. According to Christensen (1997), customers in the mainstream market continuously demand the product with a higher performance from incumbent firms. This brings the second issue that incumbent firms keep investing aggressively in technologies in their research and development department in order to provide what their customers want. The third, incumbent firms are looking for higher margins and the fourth, those leading firms are targeting larger markets rather than smaller ones.

Danneels (2004) criticizes, “... managers and scholars need to be able to distinguish disruptive from sustaining technology. What makes a technology disruptive? What are the exact criteria for identifying a 
disruptive technology? Christensen does not establish clear-cut criteria to determine whether a given technology is considered a "disruptive technology" (p. 247). Tellis (2006) concluded that Christensen's thesis could be formally tested once a precise definition of disruptive technology is adopted.

Christensen (2006, p. 45) responded above criticisms by stating "Although Dannels (2004) and others express concern that the model does not provide the ability to predict what will happen, their fear is unfounded. It is true that one cannot think a thought before it has been thought..., The theory must provide the ability to predict what will happen to the incumbents and entrants in the future if they take different actions relative to the innovation." Christensen (2006, p. 48) also stated "It would be helpful if Tellis would publish an article predicting which of our predictions will prove false and which will be borne out, based upon which firms he judges to be guided by leaders who possess the requisite vision and which are not. I extend this invitation to him in an honest and sincere way."

\section{The paradox of sustaining innovation}

In fact, sustaining innovations are at the start of disruptive innovations. This is the nature of innovations. By the time, disruptive innovations adopt sustaining innovations. This is an ongoing innovation paradox, whether the nature of innovation is sustaining or disruptive. For example, versions of Windows Operating Systems (i.e. Windows 8 , Windows 10 ) are examples of sustaining operating system developments. It's not creating an entirely new market.

Making the right choice on types of innovation is vital in any firm. Unfortunately, this is a paradox. Firms can experience a paradox when they need to make a decision. Disruptive innovations prepare an entirely new market, as said before, on the one hand, on the other hand, sustaining innovations are usually developed by incumbent firms for the mainstream market. The paradox here is whether a firm should invest in sustaining or disruptive innovations or both. Another dilemma is that having both departments (i.e. sustaining innovation department and disruptive innovation department) in a firm increases costs.

For this reason, this study aimed to explore the antecedents of sustaining innovations. Then it is important to define the term. Kayak (2017) defines a sustaining innovation as "... a measurement of the degree of "newness of a new product version", which replaces the existing player... The perceived brand is the customer's perception of sustaining innovativeness. Therefore, perceived brand sustaining innovativeness is a measurement of consumer's perception of the degree of "newness of a new product version", which replaces an existing player (p. 3-4).

If a sustaining innovation underperforms mainstream demand it is likely that sustaining innovation strongly contributes to the perceived brand innovation of the firm. Conversely, if a sustaining innovation outperforms mainstream demand it is likely that sustaining innovation poorly contributes to perceived brand innovation of the firm (Christensen, 1997).

If sustaining innovation outperforms mainstream demand, then the firm should focus on the emotional and social value of the products. Conversely, the firm should focus on functional features of the product till the firm catches the performance demanded by the mainstream market. If the functional value of the product is above performance demanded by the mainstream market then consumers no more perceive the brand as more innovative. For example, if a smartphone's 1 terabyte hard drive is adequate for consumers, if a product is made 10 terabytes, the consumer no longer sees this brand as innovative. 


\section{Antecedents of sustaining innovation}

This study develops three constructs namely; social, emotional and functional value that represents the antecedents of sustaining innovations, as shown in Figure 1 (Sweeney \& Soutar, 2001) Value creation widely discussed in the literature and is often a part of organizations' mission statements and objectives (Sweeney \& Soutor, 2001). According to Sweeney and Soutar (2001), social value is "the utility derived from the product's ability to enhance social self-concept". Emotional value is "the utility derived from the feelings or affective states that a product generates", Functional value is "the utility derived from the perceived quality and expected performance of the product" (p. 211). They developed this scale based on factor analysis. They extend our knowledge of perceiving consumer value by developing and testing a perceived value scale. They found that the scale was found to help significantly in explaining attitudes and behavior.

Similar study was conducted by Gallarza and Saura (2006). They investigated, the first, the dimensionality of consumer value in a travel-related context (students' travel behaviour), second, they explored the relations between consumer perceptual constructs such as perceived value, satisfaction, and loyalty. The results confirm the existence of a quality-value-satisfaction-loyalty chain and illustrate the complexity of value dimensions that have been shown to be highly sensitive to the experience. This study argues that these three variables (i.e., social value, emotional value, functional value) are the antecedents of perceived brand sustaining innovativeness (Sweeney \& Soutar, 2001).

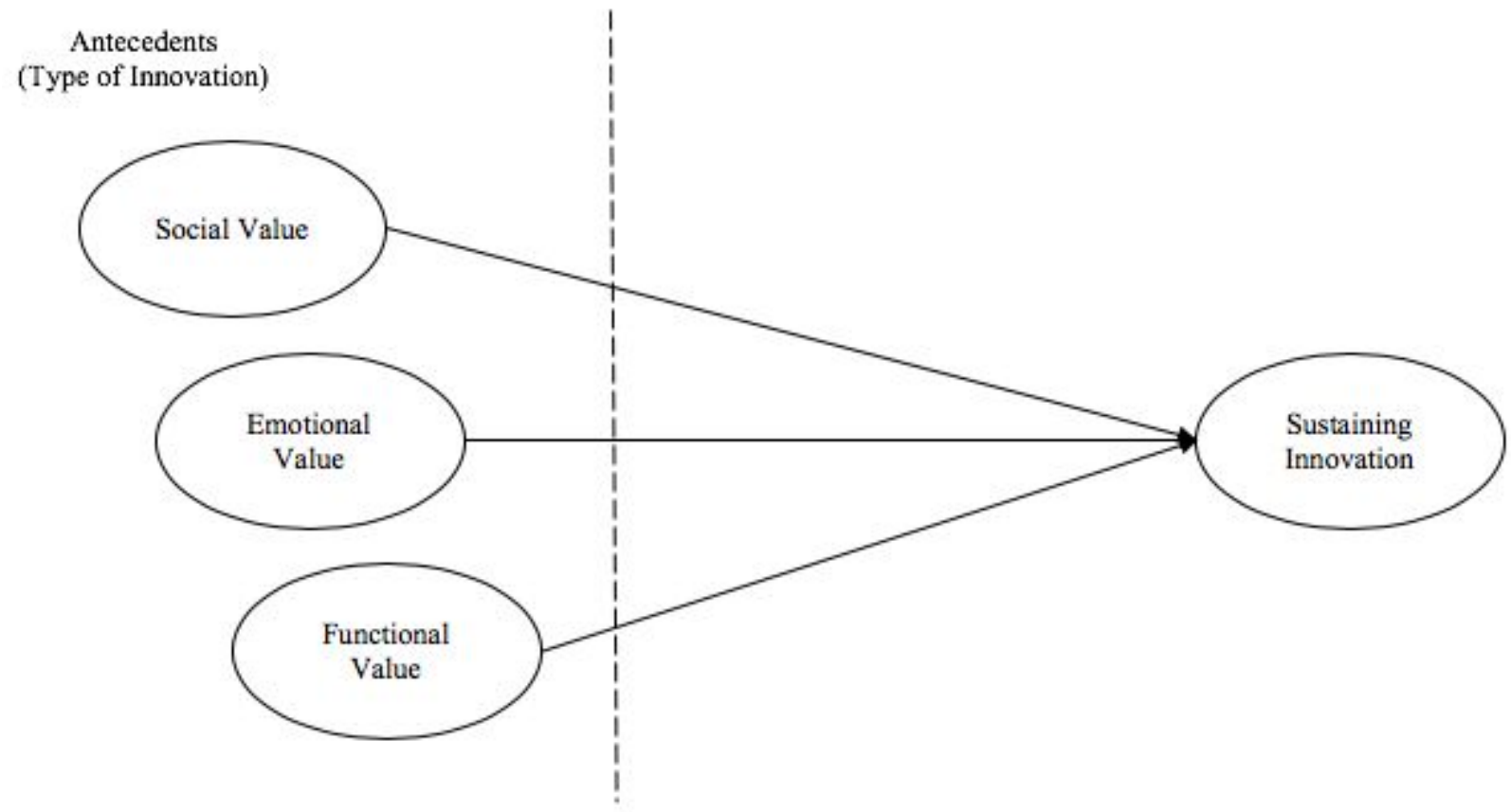

Figure. 1. Antecedents of Sustaining Innovation (Kayak, 2017).

Table 1 demonstrates the differences between sustaining innovations and disruptive innovations. It is important to understand that "disrupters start by appealing to low-end or unserved consumers and then migrate to the mainstream market" (Christensen et al., 2015). 
Table 1.

Differences between sustaining innovations and disruptive innovations

\begin{tabular}{l|ll} 
Variables & Sustaining innovations & Disruptive innovations \\
\hline Market & Mainstream and high-end market & New or low-end market \\
Performance & Good & Worse at the beginning \\
Price & Expensive & Cheaper \\
Firm size & Usually incumbent firms & Usually new ventures \\
\hline
\end{tabular}

\section{Theoretical Implications}

The innovator' dilemma has been popularized by Christensen. Although past research provided important contributions to the literature, specific types of innovation are not undertaken (e.g., Kim et al., 2015; Kunz, et al., 2011). For example, Kim et al., (2015) focused "perceived firm innovativeness" as a variable in their study. However, understanding the different types of innovations are important as different types of innovations requires a business model (Markides, 2015). Furthermore, as Garcia and Calantone (2002) argued, new innovations smell just as sweet by any other name. There is a need for an in-depth understanding of a particular type of innovation (e.g., sustaining innovation, disruptive innovation, radical innovation, breakthrough innovation).

Prange and Schlegelmilch (2018) argued that "It is very difficult for managers to compare innovation types. Most research on innovation strategy is not particularly helpful because it classifies innovation types after the company has successfully or unsuccessfully implemented them" (p. 2) From this standpoint, this study highlighted the differences between sustaining and disruptive innovations and offered a new perspective on sustaining innovation by defining it. Secondly, this paper provides a conceptual model for the antecedents of sustaining innovations. In particular, this study argued that social, emotional and functional value are the antecedents of sustaining innovations (Sweeney \& Soutar, 2001). With the complexity of understanding of sustaining innovation, these results might be helpful for the researchers in the innovation field.

\section{Practical Implications}

Firms' aims are to make competition irrelevant (e.g., Kim \& Mauborgne, 2005; Moon 2010). In order to prepare a blue ocean strategy (Kim \& Mauborgne (2005), this research focused on the "perception" of sustaining innovation. It is important to understand a specific type of innovation for analyzing firm performance (Christensen, 1997). The findings of this study highlight that social value and emotional value can be a responding strategy for outperforming products in the market. If a firm's product underperforms the mainstream market, then the firm additionally can focus on the functional value of the product.

Understanding customers' needs and wants are essential for firms. For example, although $10 \mathrm{gb}$ is enough for customers' smartphones, if a firm offers $100 \mathrm{gb}$ for customers, customers will not perceive this 
brand as much as innovative anymore. In this case, the firm should focus on the social and emotional value of sustaining innovations. Based on the definition of sustaining innovativeness as "... a measurement of the degree of "newness of a new product version", which replaces the existing player." (Kayak, 2017, p. 3), it is easy for firms to understand the product perception levels from the perspective of customers. If a firm uses two types of innovations at the same time by building two different departments for sustaining and disruptive innovations, the firm can eventually focus on building two different types of the brand for each of them. This will help the firm have more market share than its rivals.

Innovation allows a firm to develop a unique product or service. It is important to note once again that does not mean being innovative lets the firm perform better (Kim et al., 2015). The notable distinction among innovation types is crucial (Kunz et al., 2011). Over the last few decades, researchers have put a lot of effort into understanding what is innovation and what are really different types of innovations (Garcia \& Calantone, 2012; Danneels, 2004; Schmidt \& Druehl, 2008; Tellis, 2006; Yu \& Hang, 2010). This study's results might be helpful for firm managers.

\section{CONCLUSIONS}

Making the right decision on innovation types (e.g., sustaining innovation, disruptive innovation, continuous innovation, breakthrough innovation, radical innovation and etc.) requires an in-depth understanding of innovation types. In this paper, I focused on the notable distinction between sustaining innovations and disruptive innovations. From this standpoint, first, this paper aimed to highlight the differences between sustaining and disruptive innovations. Secondly, this paper provided a conceptual framework for the antecedents of sustaining innovations. Social value, emotional value, and functional values are formed as sustaining innovations antecedents (Sweeney \& Soutar, 2001). This study suggests that based on the product performance firm managers can focus on these values which allow them to reduce the cost by investing the right strategy. Research findings might be helpful in the literature.

Acknowledgment: This study is a part of a doctoral dissertation submitted to the University of Naples Federico II. Author wants to thank the University.

\section{References}

Bartel, C. A., \& Garud, R. (2009). The role of narratives in sustaining organizational innovation. Organization Science, 20(1), 107-117.

Christensen, C. M. (1997). The innovator's dilemma: When new technologies cause great firms to fail. Boston: Harvard Business Press.

Christensen, C. M., \& Overdorf, M. (2000). Meeting the challenge of disruptive change. Harvard Business Review, 78(2), 66-77.

Christensen, C. M., Raynor, M. E., \& McDonald, R. (2015). What is disruptive innovation. Harvard Business Review, 93(12), 44-53.

Danneels, E. (2004), Disruptive technology reconsidered: A critique and research agenda. Journal of Product Innovation Management, 21(4), 246-258. 
Gallarza, M. G., \& Saura, I. G. (2006). Value dimensions, perceived value, satisfaction and loyalty: an investigation of university students' travel behavior. Tourism Management, 27(3), 437-452.

Garcia, R., \& Calantone, R. (2002). A critical look at technological innovation typology and innovativeness terminology: a literature review. Journal of Product Innovation Management, 19(2), 110-132.

Kayak, M. (2017). The effects of perceived brand sustaining innovativeness on firm performance. Doctoral Dissertation, University of Naples Federico II, Naples, Italy.

Kim, J., Kim, K. H., Garrett, T. C., \& Jung, H. (2015). The contributions of firm innovativeness to customer value in purchasing behavior. Journal of Product Innovation Management, 32(2), 201-213.

Kim, W. C., \& Mauborgne, R. (2005). Blue ocean strategy: How to create uncontested market space and make the competition irrelevant. Boston: Harvard Business School Press.

Kunz, W., Bernd, S., \& Meyer, A. (2011). How does perceived firm innovativeness affect the consumer? Journal of Business Research, 64(8), 816-822.

Markides, C. (2006), Disruptive Innovation: In Need of Better Theory. Journal of Product Innovation Management, 23(1), 19-25.

Moon, Y. (2010). Different: Escaping the competitive herd. New York: Crown Business.

Prange, C., \& Schlegelmilch, B. B. (2018). Managing innovation dilemmas: The cube solution. Business Horizons, 61(2), 309-322.

Reinhardt, R., \& Gurtner, S. (2015). Differences between early adopters of disruptive and sustaining innovations. Journal of Business Research, 68(1), 137-145.

Schmidt, G. M., \& Druehl, C. T. (2008). When is a disruptive innovation disruptive? Journal of Product Innovation Management, 25(4), 347-369.

Sweeney, J. C., \& Soutar, G. N. (2001). Consumer perceived value: The development of a multiple item scale. Journal of Retailing, 77(2), 203-220.

Tellis, G. J. (2006). Disruptive technology or visionary leadership? Journal of Product Innovation Management, 23(1), 34-38.

Yu, D., \& Hang, C. C. (2010). A reflective review of disruptive innovation theory. International Journal of Management Reviews, 12(4), 435-452. 